\title{
SPECIALIST EXPERTISE ON SURGERY PLANNING
}

Playing a central role in Henry Schein Minerva's business is their Field Sales Consultants (FSCs), who provide the regular, local contact that dentists need to make sure their practices run as smoothly and efficiently as possible.

Each FSC can call on an array of colleagues with specialist expertise and in-depth knowledge on a range of topics including: new technology, lasers, CEREC, decontamination, equipment, surgery planning and practice management software, directing dentists to the person or department most appropriate to their needs.

Henry Schein Minerva continues to develop reliable and innovative partnerships with the world's leading manufacturers, offering exclusive deals on the everyday items practices purchase most. In addition, an outstanding range of high quality, own-brand consumables provides great value for those practices that want to take advantage of this option.

www.henryschein.co.uk

\section{CLEAN AND COMPLIANT CABINETS}

Classic Dental Cabinetry (CDC) can supply 'off-the-shelf' solutions for worktops, sinks and taps tackling the major areas of compliance, leaving practitioners free to concentrate on dentistry. Alternatively they can provide full 'bespoke' solutions suitable for the smallest spaces to complete new-builds.

The Classic Dental Cabinetry range features quality post-formed worktops, PVC edged doors and carcase fronts, quality sinks and mixer taps - all designed on a bespoke basis. CDC can include split height designs for superior ergonomics, custom instrument drawers which lock in the open position, custom suction motor housings, CVS tip support modules, tray storage and single cabinetry runs for smaller surgeries.

CDC is extremely competitively priced and available either 'supply only' or with full installation support. It is designed to suit every budget without compromising on form or function.

For further information email info@ classicdentalcabinetry.co.uk or visit www.classicdentalcabinetry.co.uk.

\section{DON'T LET PANDAS EAT YOUR UNIFORM}

Natural Fabrics Clothing uses an exclusive mix of bamboo and organic cotton for its range of work uniforms, resulting in a range of unique green and practical benefits.

For over 70 years petrol-based synthetic fabrics have formed the basis for work wear, in particular uniforms, throughout the UK and the world, with cheap Far East production dominating the market. Natural Fabrics uses a 70\% bamboo and 30\% organic cotton mix which will bring all of the benefits of natural fibres such as antibacterial properties alongside being hypoallergenic and anti-fungal - perfect for sensitive or allergy prone skin. As well as being more caring for the wearer, the fabrics hold excellent environmental credentials as they are fully biodegradable and compostable.
Bamboo is the fastest growing plant in the world and spreads rapidly across large areas; it grows naturally without the use of pesticides or fertilisers; is cut, not uprooted, which helps soil stability; grows on hill slopes where nothing else is viable; yields ten times more fabric per acre than cotton; and has a tiny water requirement unlike some other crops such as cotton.

Visit www.naturalfabricsclothing.

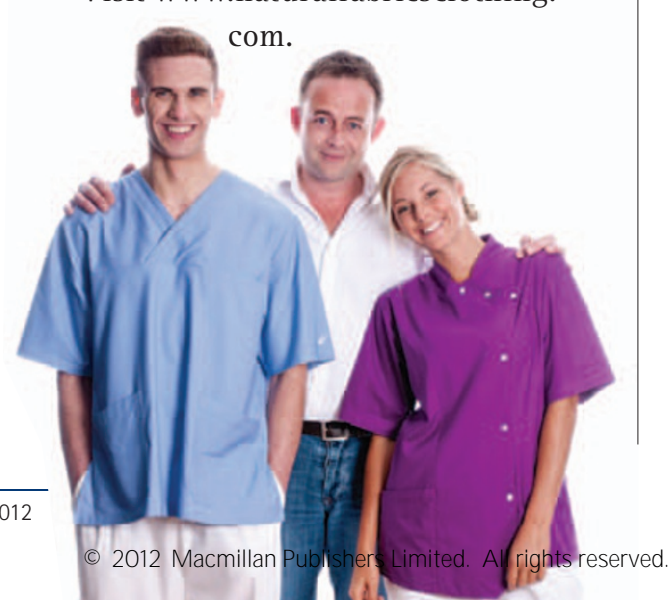

